Article

\title{
Energy Implications of Lot Sizing Decisions in Refrigerated Warehouses
}

\author{
Beatrice Marchi ${ }^{1}\left(\mathbb{D}\right.$, Simone Zanoni ${ }^{1, *(\mathbb{D}}$ and Mohamad Y. Jaber ${ }^{2}$ \\ 1 Department of Mechanical and Industrial Engineering, Università degli Studi di Brescia, Via Branze, 38, \\ I-25123 Brescia, Italy; beatrice.marchi@unibs.it \\ 2 Department of Mechanical and Industrial Engineering, Ryerson University, Toronto, ON M5B 2K3, Canada; \\ mjaber@ryerson.ca \\ * Correspondence: simone.zanoni@unibs.it
}

Received: 5 March 2020; Accepted: 1 April 2020; Published: 5 April 2020

\begin{abstract}
Cold supply chains (CSCs) are responsible for preserving the quality of perishable goods in storage and transport. They consume significant amounts of energy to maintain cooling temperatures constant over time continuously and ubiquitously, which is affected by the surrounding environment and the users' behavior. The storage filling level is one specific feature of refrigerated warehouses observed in practice: they are more energy efficient when kept full of items, reducing the space that air occupies. Inventory management models that consider energy consumption have received increasing attention recently due to an increase in stakeholders' awareness of sustainability. Despite this interest, there is no work that jointly considers the effects of the filling level and the temperature inside the warehouse. This study, therefore, integrates those aspects into the economic order quantity model and finds the optimal lot size quantity that minimizes the total system cost, which is the performance measure used herein. It provides numerical results and brings some insights into the behavior of the model proposed.
\end{abstract}

Keywords: inventory management; economic order quantity; cold chain; refrigerated warehouse

\section{Introduction}

Cold supply chains (CSCs) contribute significantly to global warming as they consume enormous amounts of cooling energy to refrigerate perishable products to preserve their quality during storage and transportation and to provide customers with safe and wholesome products [1]. Approximately 15\% of the total energy, worldwide, is associated with CSCs and other cooling systems [2]. This percentage share will grow in the coming years due to the increase in population, and, subsequently, consumption (more refrigeration), as well as requirements on quality, hygiene, and safety standards. For instance, in the food and beverage sector, $40 \%$ of all deliveries require refrigeration [3], with a $60 \%$ increase in food demand expected by 2050 [4]. Hence, the growth in global food demand and, subsequently, establishing more CSCs will put more pressure on energy resources [5]. Furthermore, currently, only a limited share, of about $16 \%$, comes from renewable sources, which influences the sustainability and the economic performance of these supply chains.

CSCs preserve and transport perishable goods through all their stages to customers. Those products have short shelf lives and are highly sensitive to the conditions of their surrounding environment (i.e., temperature, humidity, and light intensity). Hence, they require special equipment and facilities (e.g., refrigeration and dehumidification systems) throughout the CSC stages to sustain the prescribed environment [6]. Logistics and warehousing activities consume energy the most since they require continuous and ubiquitous refrigeration. For instance, in supermarkets, around $45 \%$ of the electricity is used for chilled and frozen food storage in cabinets and cold rooms [7], for which user behavior is 
the highest contributor (such as the frequent opening of a refrigerator door and its filling level) $[8,9]$. Specifically, refrigerated warehouses should be kept as full as possible to perform more efficiently and to reduce energy consumption. Despite its importance, the literature reports a few articles that study the effect of the filling level on the energy consumption of residential, not commercial, refrigerators. In the above-described context, energy consumption from warehousing activities becomes vital in the inventory decision-making process, since, in CSCs, it is responsible for a significant share of the overall costs, and hence, it can affect the optimal inventory policy and vice versa. The literature also shows that no study investigated the joint effect of the difference in temperature (between inside the refrigerated unit and its ambient condition) of a warehouse and its filling level on energy consumption. This paper does so by investigating the effect of energy consumption on the economic order quantity (EOQ) when products are preserved by being stored in a refrigerated warehouse. The temperature setting inside the warehouse, to guarantee the preservation of perishable products, and the duration in storage determine the level of energy demand, where a lower filling level results in higher energy consumption. This paper presents an inventory model that accounts for ambient and storage temperatures, storage time, and the storage filling level to study their effects on energy consumption and inventory decisions, i.e., lot size quantity and the total system cost. The rationale for using the EOQ, introduced by Harris in 1913 [10], is that it is a well-established and robust model in the operations management literature when dealing with inventory from the perspective of a single firm. It finds the optimal order quantity that minimizes the sum of the ordering and holding costs. Later on, Zavanella et al. [11] extended this model by integrating an energy-related objective into the model.

The remainder of the paper has the following structure. Section 2 provides a review of the literature on the topics relevant to the study (i.e., energy considerations in inventory decisions and the cold chain). In Section 3, the model proposed is developed. Section 4 presents a numerical analysis to illustrate the behavior of the model and to gain general insights. Finally, Section 5 summarizes the main findings and defines future developments.

\section{Literature Review}

This section presents an overview of the relevant literature. This work considers a company in a CSC and focuses on (i) inventory and energy requirement decisions and (ii) performance evaluation and the CSC management.

\subsection{Energy Considerations in Inventory Decisions}

The increased awareness of sustainability along with stringent restrictions that governments have been imposing on energy consumption and greenhouse gas emissions have generated a challenging interest among practitioners and researchers who have been trying to improve systems performance. This overview, specifically, focuses on inventory models that considered energy requirements. Zavanella et al. [11] extended the economic production quantity (EPQ) and the joint economic lot size (JELS) models by considering energy usage in processes with variable production rates. They investigated two coordination agreements, the traditional, which keeps most inventory at the vendors, and a vendor managed inventory (VMI) agreement with consignment stock (CS), which has the opposite inventory behavior. They studied injection molding, which is an energy-intensive process, and their numerical results showed that high energy costs had to do with operating the process at different production rates. They also showed that adopting a VMI-CS policy may significantly lower those costs. Moreover, Zanoni and Zavanella [12] developed a model to configure a sustainable food supply chain consisting of a distributor that procures and stocks chilled or frozen products from a producer, who also freezes or chills them and transports them to different retailers. They considered the quality (level of degradation) of food products, which depends on the storage time and temperature, and its impact on the chain's costs and sustainability. Their results showed a trade-off between temperature (energy requirements) and total costs. Lower temperatures slow the degradation and reduce food 
waste, but increase costs. Their work demonstrated how the needed amounts of energy impact the effectiveness and sustainability of a food supply chain.

This research area mainly considered energy usage in forward and closed-loop supply chains with manufacturing and/or remanufacturing activities. For instance, Hasanov et al. [13] developed a mathematical model to find the production and inventory policies that minimize the total cost of a four-level supply chain with a reverse channel consisting of an inspection and disassembly center and a remanufacturing center. Bazan et al. [14] reviewed reverse logistics EOQ/EPQ and JELS mathematical inventory models, paying special attention to environmental issues (e.g., waste disposal, greenhouse gas emissions, and energy consumption). Marchi et al. [15] studied the effect of controllable production rates that improve with learning on energy efficiency and the lot sizing policy. Another relevant article studied how imperfect production processes increase energy consumption due to unnecessary rework and machine downtime [16]. A recent study investigated a lot sizing policy when wasted heat from an energy-intensive process is recovered and used to operate the system [17], and another one approached the problem from a supply chain perspective [18]. Table 1 presents a summary of the related literature.

Table 1. Summary of related literature for inventory models with energy consideration.

\begin{tabular}{ccccc}
\hline Reference & Inventory Model & Energy Aspects & Activities & Refrigeration \\
\hline$[11]$ & EPQ, JELS & SEC $(P)$ & Production & - \\
{$[12]$} & JELS & SEC $(T)$ & Production and logistic & yes \\
{$[13]$} & CLSC & SEC $(P)$ & Production and rework & - \\
{$[14]$} & EPQ, JELS & SEC $(P)$ & Production & - \\
{$[15]$} & EPQ & SEC $(P)$ & Production and rework & - \\
{$[16]$} & JELS & SEC $(P)$ & Production and rework & - \\
{$[17]$} & EPQ & Heat recovery & Production & - \\
{$[18]$} & JELS & SEC $(P)$ Heat recovery & Production & - \\
This study & EOQ & SEC $\left(I_{\max }, T, f\right)$ & Logistic & yes \\
\hline
\end{tabular}

Notes: EPQ: economic production quantity, JELS: joint economic lot size, CLSC: closed-loop supply chain, f: filling level, P: production rate, T: temperature, W: warehouse size, SEC: specific energy consumption.

\subsection{Cold Chains Evaluation}

The investigation of CSCs (i.e., those of perishable products that heavily use refrigeration) through an inventory theory approach is a very recent topic. Despite that lot sizing for perishable products has been extensively studied in the literature, few studies took a supply chain approach. Those studies were focused mainly on network design and environmental issues. For instance, Zanoni et al. [19] developed an analytical model to evaluate and optimize the design of an eco-efficient refrigerated distribution network of vegetables by including inventory holding, transportation, and energy consumption costs. Their results showed that increasing the number of distribution centers decreased supply chain costs, but increased the environmental implications. They did not obtain the optimal solution, but rather suggested how to reach the desired economic and environmental performance of the distribution centers. Their results also indicated that, unlike the lot size, temperature significantly impacts performance. One limitation of their work was that they did not consider the locations of the distribution centers. Saif and Elhedhli [20] developed a bi-objective cold supply chain design problem, economic and environmental, which measured the average $\mathrm{CO}_{2}$ emissions from shipping products (plant to the warehouse) and the leakage of refrigerant during transport, which has a high global warming potential. Their objective was to find the best design that jointly minimized storage, inventory, and transportation costs. Their results showed that it was possible to slash GHG emissions without significant increases in costs. Wei et al. [21] extended the inventory routing problem for a cold chain distribution network characterized by short replenishment periods and economic concerns: (i) expensive investment in refrigerating at the warehouses, (ii) the implementation of a vendor-managed inventory to preserve the freshness of vegetables and produce, and (iii) distribution costs relating to the vehicle travel and cold storage costs. Their results suggested logistics operations be performed by a third party and sharing logistics resources (e.g., capacity) to reduce costs further. Meneghetti 
and Ceschia [22] studied a refrigerated routing problem, involving multi-drop deliveries of palletized unit loads of frozen food from a central depot to clients. The purpose of their study was to select the route with the minimum fuel consumption for both traction and refrigeration, linking both to outdoor temperature and congestion in different time windows of days and seasons. Their results of a local network for frozen bread and dough deliveries to supermarkets showed that traction requirements overcame those of refrigeration and were affected by the variation in truckload and suggested that reducing traction consumption rather than improving the refrigeration process resulted in better energy efficiency. Hariga et al. [23] proposed three models with different objectives; economic, environmental, and a hybrid of the two, to minimize carbon emissions in transportation and storage activities in a cold supply chain, consisting of a plant/warehouse, a distribution center, and a retailer. They found that having different carbon taxes required adjusting the operational policy, which slightly increased costs. They suggested focusing on where savings in carbon emissions resulted in a reduction in total system cost. Bozorgi et al. [24] developed a new inventory model for cold items, stored at ambient temperatures, by considering temperature-controlled environments associated with storage and transport, with GHG emissions generated from storage and transportation activities. Their results showed that for different values of the ratio of the holding cost of a freezer to the shipment unit transport cost, their model produced a different order quantity than the EOQ model. They also showed that for small values of the unit purchase cost, the two models differed significantly, and increasing the unit price resulted in the opposite behavior. In a follow-up paper, the last to be discussed here, Bozorgi [25] developed their model in [23] to consider multiple cold items, where they grouped items by families of shared storage and transportation. They determined the inventory policy for each family that reduced costs and GHG emissions and suggested not to transport those items requiring different storing temperatures using the same refrigerated truck. His results indicated that with the variation in the values of the cost/emissions function parameters, the number of different products also increased.

\section{Model Development}

\subsection{Problem Setting and Assumptions}

This article considers a problem of a refrigerated warehouse with capacity $I_{\max }$ exhibiting economies of scale to counter overhead and amortized capital expenditure costs [26]. It assumes a single cold product whose inventory is replenished every $\tau$ units of time. Let $C\left(I_{\max }\right)=C_{0}+C_{1} I_{\max }-b$. be the cost of building and operating the refrigerated warehouse of capacity $I_{\max }$, where $C_{0}$ is a fixed cost associated with operating the warehouse, $C_{1}$ is a variable warehousing cost per $\mathrm{m}^{3}$ of storage affected by the economies of scale, and $b$ is a parameter defining the impact of the economies of scale. The main assumptions for the model development are reported as follows:

- The lead-time is zero. Technically, an order could be set a day before when inventory is positive and delivered overnight [27].

- The demand $D$ is constant over time.

- The temperature of items remains unchanged from the moment they leave the warehouse until they enter the buyers and do not require any chilling treatment. Regulations define storage and transport temperatures for each product.

- At steady-state, a minimum level of stock, i.e., $S$ units, is always kept in the refrigerated warehouse. Shipments are of size $Q$ each and occur every time that the inventory level of the warehouse reaches the minimum level of stock. The rationale for assuming a minimum level of stock is that full warehouses have less air room to be refrigerated, and subsequently, as mentioned earlier, less energy is consumed $[8,9]$. $S$ represents the minimum amount of goods kept in warehouse storage and is a decision variable.

- Stock is assumed to be handled on a first-in-first-out (FIFO) basis to preserve its freshness [28]. That is, $S$ items remaining from a previous shipment are moved closer to the door of the refrigerator to be withdrawn first, and newly received items are pushed behind $S$, abiding with 
FIFO. The frequency and for how long a door is opened are known, generally, to affect the cooling performance of refrigerators, especially for household refrigerators. Several authors have noted a heat gain caused by door openings and, consequently, an increase in a refrigerator's energy usage [29]. The door size here us not significantly related to the size of the warehouse (in contrast to the household refrigerator, where the door size represents a significant portion of the overall surface). Moreover, solutions, such as air curtains, may be installed to reduce cooling loss from opening the refrigerator door. Therefore, opening a refrigerator door has a negligible effect on its cooling performance, and, therefore, ignored.

- Finally, it is also assumed that the shelf life of the product is considerably longer than the length of the consumption cycle, $\tau$. This means that the freshness and quality of the foodstuff are maintained constant; thus, no degradation is experienced.

Figure 1 shows the inventory level of the warehouse over time.

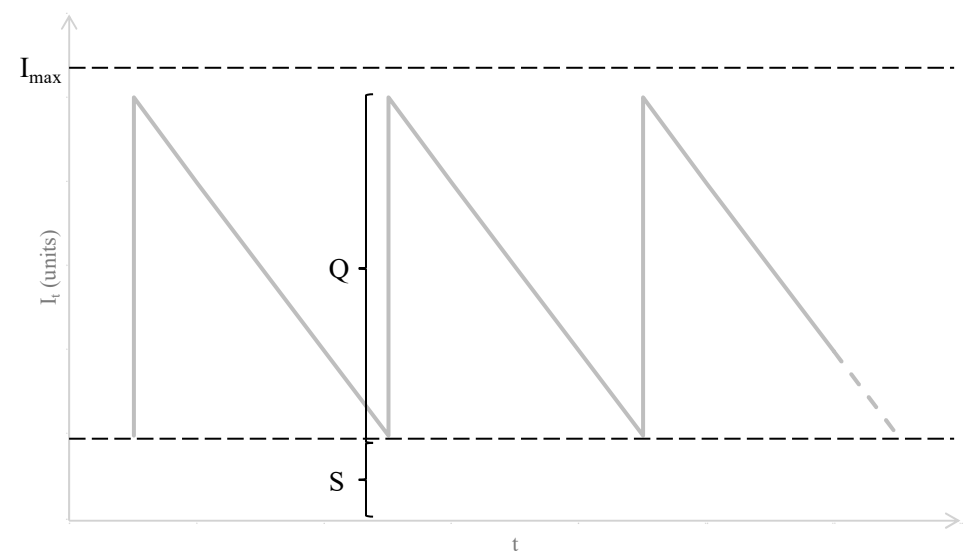

Figure 1. Inventory level over time.

\subsection{Model Formulation}

The cost function includes the unit-time order, $A \cdot D / Q$, and the holding, $h \cdot A I L(Q, S)$, costs, where $\operatorname{AIL}(Q, S)$ is the average inventory level per unit-time and equals $S+Q / 2$. The total holding cost consists of two components, physical and financial. The first includes the operational costs of managing the warehouse (i.e., storage space, labor, auxiliary services, and insurance). The second represents the cost of money tied up in inventory.

Full refrigerated warehouses are more energy efficient than the empty ones, as has already been discussed. Thus, to take into account this aspect, the total cost includes the cost to keep the product in a refrigerated state, which is defined as $c_{e} \cdot \int_{t=0}^{\tau} \operatorname{SEC}\left(T_{w}, I(t), I_{\max }\right) \cdot I(t) d t$, where $c_{e}$ is the cost of cooling energy $(\$ / \mathrm{kWh})$ and $\operatorname{SEC}\left(T_{t}, I(t), I_{\max }\right)$ is the specific energy consumption $\left(\mathrm{kWh} / \mathrm{m}^{3}\right)$ at temperature $T_{w}$ calculated for every inventory level point, $I(t)$, where $0<t<\tau$ and $S \leq I(t) \leq I_{\max }$.

Earlier studies identified ambient and cooling temperatures, the design of the storage area and how it is constructed, and how a refrigerated warehouse is operated, as the main factors affecting the energy consumption [30]. The specific energy consumption, generally, reduces as warehouse storage increases, and it can be defined as:

$$
S E C_{T_{r}}\left(I_{\max }\right)=\alpha I_{\max }{ }^{-\beta},
$$

where $T_{r}$ is the reference temperature at which the SEC is evaluated and is affected by the parameters $\alpha$ and $\beta$.

Few studies have investigated the effect of the filling level of refrigerated warehouses or freezers on energy consumption empirically; those that did only focused on residential refrigerators. The filling level is the percentage of the warehouse storage volume $(V)$ that the quantity of a refrigerated product 
occupies, and it is affected by $S, Q$, and $V$. Hence, the formulation of how the utilization rate affects $S E C$, defined in Equation (2), was based on empirical data and observations.

$$
\operatorname{SEC}\left(T_{r}, I(t), I_{\max }\right)=S E C_{T_{r}}\left(I_{\max }\right)+\delta\left(1-\frac{I(t)}{I_{\max }}\right)^{\gamma},
$$

where the first term is given by Equation (1), while the second term defines the increase in the specific energy consumption due to the utilization of the warehouse not being full (i.e., when the filling level is lower than 1), which is a function of the two coefficients $\delta$ and $\gamma$.

Furthermore, the specific energy consumption should be adjusted, as defined in Equation (3) below, to consider the actual temperature, where the input data determine the reference temperature point. Deviations from this value affect energy consumption, where lower (higher) cooling temperatures increase (reduce) the SEC.

$$
\operatorname{SEC}\left(T_{w}, I(t), I_{\max }\right)=\operatorname{SEC}\left(T_{r}, I(t), I_{\max }\right) \cdot \rho_{T_{w}},
$$

where $\rho_{T_{w}}=\frac{\operatorname{COP}_{T_{r}}}{\operatorname{COP}_{T_{w}}}$ and $C O P_{T}=\frac{T_{\text {cold }}}{T_{\text {hot }}-T_{\text {cold }}}$. Specifically, $T_{\text {hot }}$ and $T_{\text {cold }}$. are the absolute temperatures of the hot and cold heat reservoirs, respectively. For the sake of simplicity, it is possible to consider $T_{h o t}$ as the average outside temperature of the warehouse environment at the locations of the cold chain actors (named $T_{a m b}$, i.e., $T_{a m b}=T_{h o t}$ ), while $T_{\text {cold }}$ is the average temperature inside the warehouse. It should be noted that deviations in the inside temperature also affect the holding costs.

Figure 2 illustrates the behavior of the specific energy consumption for a refrigerated warehouse inside temperature, the filling level, and the storage size.

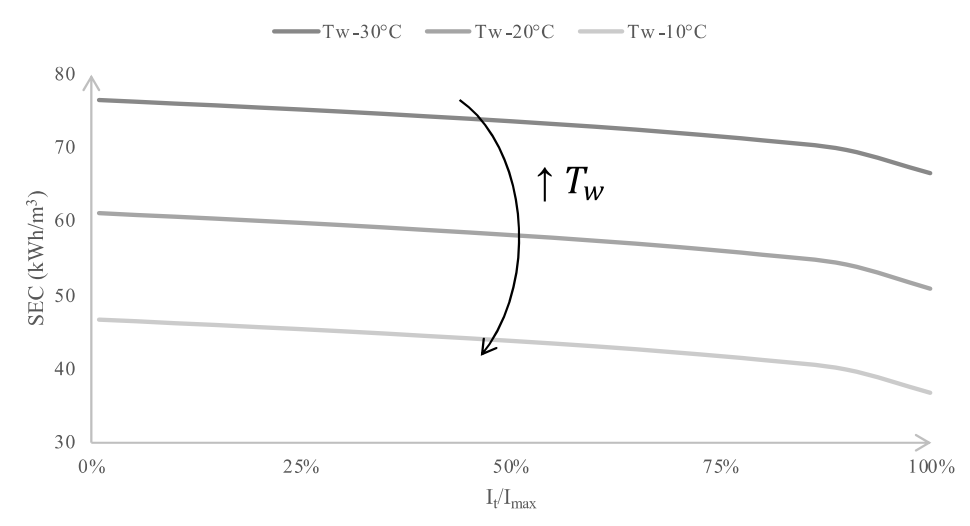

Figure 2. Specific energy consumption as a function of the filling level, $I_{t} / I_{\max }$, for different temperatures, $T_{w}$.

The company may decide the values of the lot size $(Q)$ and the minimum level to keep in stock to reduce the energy consumption $(S)$ to minimize its total cost function defined in Equation (4). The capacity of the warehouse $\left(I_{\max }\right)$ here is an input parameter.

$$
T C\left(Q, S, T_{w}\right)=A \frac{D}{Q}+h A I L(Q, S) \rho_{T_{w}}+c_{e} \frac{D}{Q} \int_{t=0}^{\tau} S E C\left(T_{w}, I_{t}, I_{\max }\right) I_{\max } d t+\frac{C\left(I_{\max }\right)}{m}
$$

Since the lifetime of the warehouse is $m$ years, the capital invested in building and equipping the warehouse is depreciated over multiple periods. For simplicity and due to the type of asset considered, we assumed a straight-line depreciation and no residual value at the end of the lifetime considered. Thus, different depreciation trends and residual values at the end of the lifetime could be considered in a further development of the model.

Note that the maximum inventory level cannot exceed the warehouse storage capacity, i.e., $I_{\max } \geq S+Q$. 
$T_{w}$ is an input parameter used to find the optimal value of the size of the order and the minimum inventory level kept in the warehouse. The objective function, defined in Equation (4), is complex in structure and does not allow an analytical optimization. An optimal value that minimizes the total cost can, alternatively, be demonstrated graphically for many sets of input parameters. A similar approach can be found in the literature [31]. The following solution algorithm is applied to find the optimal values of the decision variables:

o $\quad$ Step 1. Set $Q=1$, and $S=0$.

o Step 2. Calculate $T C(Q, S$,$) from Equation (4).$

o Step 3. Repeat Step 2 for all sets of $(Q, S)$, incrementing their values by one unit. The values of the $\left(Q^{*}, S^{*}\right)$ decision variables that minimize the total cost of the company are determined and saved as the optimal solution.

The present solution procedure can be used for different temperatures to identify the best profile of the chain in terms of cost and its sustainability relative to energy requirements and food preservation.

\section{Numerical Study}

This section presents a numerical study to illustrate the behavior of the developed model and the relevance of the considered factors. The numerical analysis is based on a case study for a logistics operator, who serves a large-scale distribution network of frozen products, by managing one of its platforms in Northern Italy. Frozen products should be kept at a temperature of $-20^{\circ} \mathrm{C}$, requiring substantial amounts of energy to refrigerate the required storage space. This subsequently affects a system's optimal inventory policy. Moreover, some of the numerical parameters were adapted from previous studies $[11,15,16]$ and adjusted for the considered case study: $A=\$ 400 /$ order, $D=1000 \mathrm{~m}^{3} /$ year, $c_{e}=\$ 0.15 / \mathrm{kWh}, h=\$ 1.5 / \mathrm{m}^{3}$ year.

The refrigerated warehouse parameters considered are: $I_{\max }=2000 \mathrm{~m}^{3}, m=20, C_{0}=\$ 100,000$, and $C_{1}=\$ 150 / \mathrm{m}^{3}$. The warehouse was equipped with an ammonia-cooled system capable of keeping the environment conditioned to maintain temperatures of $T_{w}=-20{ }^{\circ} \mathrm{C}$, while $T_{\text {hot }}=20{ }^{\circ} \mathrm{C}$ and $T_{r}=5{ }^{\circ} \mathrm{C}$, respectively. The parameters of the specific energy consumption were approximated experimentally: $\alpha=50, \beta=0.25, \gamma=0.5$, and $\delta=15$.

Figure 3 shows that the company's total cost function, i.e., $T C(Q, S)$ defined in Equation (4), was jointly convex in $Q$ and $S$ for the considered set of parameters, confirming that the optimal values of the decision variables exist. Hence, the proposed algorithm guaranteed an optimal solution. The figure shows that the optimal amount of the product available at the beginning of each cycle (i.e., $S+Q$ ) was that of the entire warehouse, as it was inefficient to keep refrigerated when the filling level was low.

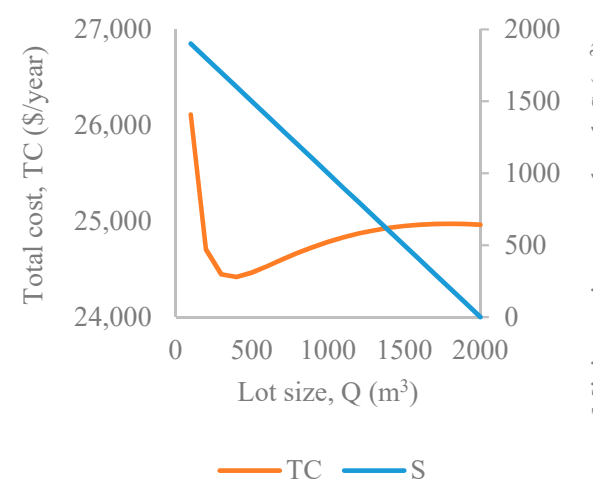

(a)

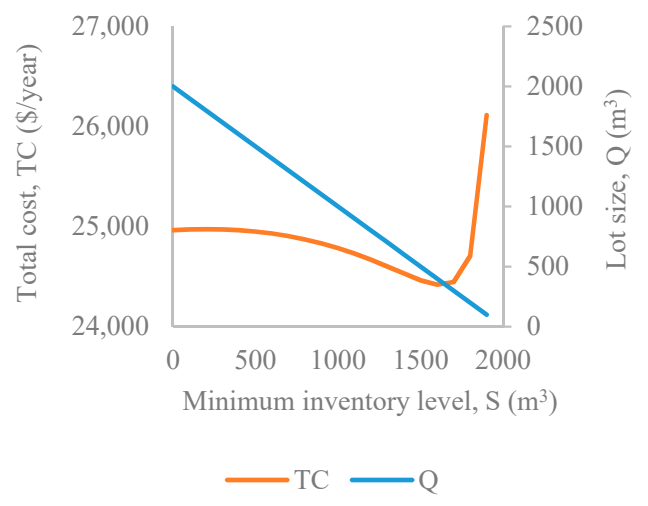

(b)

Figure 3. Total cost and (a) optimal minimum inventory level as a function of the lot size; (b) optimal lot size as a function of the minimum inventory level. 
The results presented in Tables 1 and 2 highlight the relevance of accounting for the filling level and the warehouse internal and ambient temperatures when determining lot-sizing decisions. Not doing so would result in totally different optimal values of the lot size and the minimum inventory level. Scenarios that did not consider the filling level resulted in a larger optimal lot size, $Q^{*}$, and in the warehouse becoming empty in every cycle (i.e., $S^{*}=0$ ), thus increasing the total cost by about $6 \%$ and $5 \%$ for Scenario A and Scenario C, respectively. The increase in the total cost was mainly due to a noticeable increase in energy consumption from having a zero-filling level, which overrode the savings in ordering and holding costs. Considering only the filling level, as in Scenario B, it decreased the total cost (i.e., $2.58 \%$ ) compared to Scenario C. An increase in the optimal lot size reduced the value of $S^{*}$, due to space restriction $\left(I_{\max }\right)$ and, subsequently, the order cost. It also lowered the holding cost, since, on average, the inventory level was less when $S$ approached zero. At the same time, a lower $S$ value increased the energy cost as the refrigerated warehouse was run for a longer time at a low filling level, corresponding to a higher SEC. It is also interesting to observe that Scenario C presented a lower deviation in the total cost compared to Scenario A. Hence, the effects of the two aspects considered on the total costs slightly compensated one another. It seemed it was better not to consider any of the two aspects if the temperature was the only aspect to be considered.

In the proposed model, two different aspects were jointly considered, which have not been taken into account in other studies yet.

Three scenarios were introduced to investigate the independent effects of the filling level and the temperature adjustment on the inventory policy and economic performance in comparison to the model of this paper that jointly considered both aspects. Those scenarios are presented and investigated below:

Table 2. Optimal values of the decision variables and the total $\operatorname{cost} T C\left(Q^{*}, S^{*}\right)$ for different scenarios. $\Delta$ is the percentage errors in total cost from not considering the filling level and/or temperature adjustment.

\begin{tabular}{ccccccc}
\hline & Temperature & Filling Level & $Q^{*}$ & $S^{*}$ & $T C\left(Q^{*}, S^{*}\right)$ & $\Delta$ \\
\hline This study & C & C & 371 & 1629 & $\$ 24,415.36$ & \\
Scenario A & C & NC & 427 & 0 & $\$ 25,905.79$ & $6.10 \%$ \\
Scenario B & NC & C & 2000 & 0 & $\$ 24,961.72$ & $2.24 \%$ \\
Scenario C & NC & NC & 730 & 0 & $\$ 25,625.18$ & $4.96 \%$ \\
\hline \multicolumn{7}{c}{ Notes: C = considered; NC = not considered. }
\end{tabular}

Scenario A calculated the specific energy consumption by considering the cooling temperature adjustment and ignored the filling level. Its total cost per unit time is given as:

$$
C_{a}(Q, S)=A \frac{D}{Q}+h A I L(Q, S) \rho_{T_{w}}+c_{e} \frac{D}{Q} \int_{t=0}^{\tau} S E C\left(T_{w}, I_{\text {max }}\right) I_{\max } d t+\frac{C\left(I_{\max }\right)}{m}
$$

where $\operatorname{SEC}\left(T_{w}, I_{\max }\right)=\operatorname{SEC}\left(T_{r}, I_{\max }\right) \rho_{T_{w}}$.

Scenario $B$ calculated the specific energy consumption by considering the filling level and ignored the cooling temperature adjustment. Its total cost per unit time is given as:

$$
C_{b}(Q, S)=A \frac{D}{Q}+h A I L(Q, S)+c_{e} \frac{D}{Q} \int_{t=0}^{\tau} S E C\left(T_{r}, I_{t}, I_{\max }\right) I_{\max } d t+\frac{C\left(I_{\max }\right)}{m}
$$

Scenario C ignored both the filling level and the cooling temperature adjustment. Its total cost per unit time is given as:

$$
C_{c}(Q, S)=A \frac{D}{Q}+h A I L(Q, S)+c_{e} \frac{D}{Q} \int_{t=0}^{\tau} S E C\left(T_{r}, I_{\max }\right) I_{\max } d t+\frac{C\left(I_{\max }\right)}{m} .
$$


Table 3 summarizes the optimal results for the static scenarios and compares them to those defined above. The results presented in Tables 2 and 3 highlight the relevance of accounting for the filling level and the warehouse internal and ambient temperaturewhen determining lot-sizing decisions. Not doing so would result in totally different optimal values of the lot size and the minimum inventory level. Scenarios that did not consider the filling level resulted in a larger optimal lot size, $Q^{*}$, and in the warehouse becoming empty in every cycle (i.e., $S^{*}=0$ ), thus increasing the total cost by about $6 \%$ and $5 \%$ for Scenario A and Scenario C, respectively. The increase in the total cost was mainly due to a noticeable increase in energy consumption from having a zero-filling level, which overrode the savings in ordering and holding costs. Considering only the filling level, as in Scenario B, it decreased the total cost (i.e., $2.58 \%$ ) compared to Scenario C. An increase in the optimal lot size reduced the value of $S^{*}$ due to space restriction $\left(I_{\max }\right)$ and, subsequently, the order cost. It also lowered the holding cost, since, on average, the inventory level was less when $S$ approached zero. At the same time, a lower $S$ value increased the energy cost as the refrigerated warehouse was run for a longer time at a low filling level, corresponding to a higher SEC. It was also interesting to observe that Scenario C presented a lower deviation in the total cost compared to Scenario A. Hence, the effects on the total costs of the two aspects considered slightly compensated one another.

Table 3. Variations in the cost components when compared to those produced by the model proposed in this study.

\begin{tabular}{lccccc}
\hline & Order Cost & Holding Cost & Energy Cost & Investment Cost & TC $\left(Q^{*}, S^{*}\right)$ \\
\hline This study & $\$ 1078.17$ & $\$ 7975.19$ & $\$ 10,358.49$ & $\$ 5003.51$ & $\$ 24,415.36$ \\
Scenario A & $-13.11 \%$ & $-88.23 \%$ & $83.69 \%$ & $0.00 \%$ & $6.10 \%$ \\
Scenario B & $-81.45 \%$ & $-44.89 \%$ & $48.31 \%$ & $0.00 \%$ & $2.24 \%$ \\
Scenario C & $-49.18 \%$ & $-79.88 \%$ & $78.30 \%$ & $0.00 \%$ & $4.96 \%$ \\
\hline
\end{tabular}

Since the behavior of the developed model strictly depended on the input parameters, it was necessary to perform a sensitivity analysis to gain more insights into the problem. Specifically, the total cost was the performance measure, and, therefore, it was investigated for different values of the energy cost per kWh $\left(c_{e}\right)$, the inside temperature, $T_{w}$, and the demand rate $(D)$. Furthermore, the optimal values of the decision variables and the error of not considering the effects of temperature adjustments and the filling level $(\Delta)$ were also analyzed. The results showed that a higher energy cost per $\mathrm{kWh}$ resulted in increasing the total cost and reducing the lot size (Figure 4a). As the increase in the energy cost became more relevant, it dominated other cost components (i.e., order and holding costs), which was associated with larger lot sizes. Setting the temperature inside the refrigerated warehouse too low increased the refrigeration work and, subsequently, the total cost and the value of $S^{*}$. (Figure $4 \mathrm{~b}$ ).

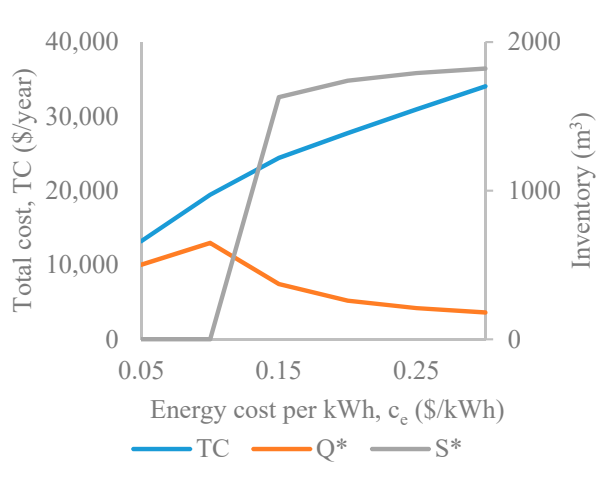

(a)

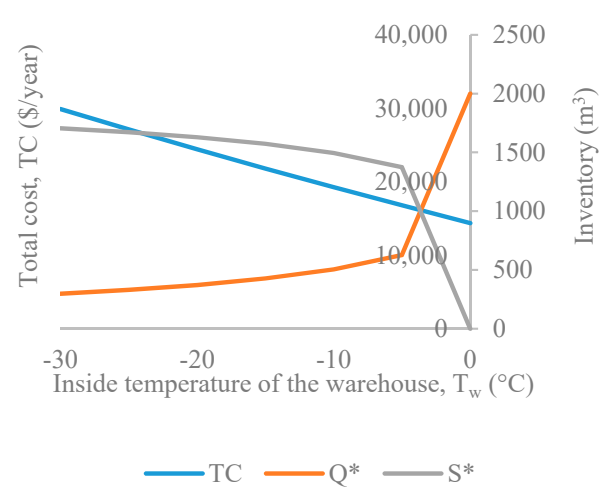

(b)

Figure 4. The behavior of the total cost and the optimum values of the decision variables, $Q^{*}$ and $S^{*}$, for changes in the values of: (a) the unit energy $\operatorname{cost}, c_{e}$ and (b) the temperature set inside the warehouse, $T_{w}$. 
Figure 5 shows the error of not considering temperature adjustments and the filling level when optimizing inventory decisions for Scenarios A, B, and C, for different values of the unit energy cost and $T_{w}$. As can be observed from the graphs, the error of not considering the fill level (Scenarios $A$ and C) increased with unit energy cost (Figure 5a), whereas Scenario B showed insensitivity. Figure $5 b$ shows that lower temperatures directly affected the error values for Scenarios B and C, which did not consider temperature adjustment. One can note that variations in temperature values indirectly affected Scenario A since $S^{*}$ was always equal to zero, which did not capture the reduction in the SEC obtained from using the model of this study, where a lower temperature resulted in a higher $S^{*}$. Note that Scenarios A and C behaved similarly for high values of $T_{w}$.

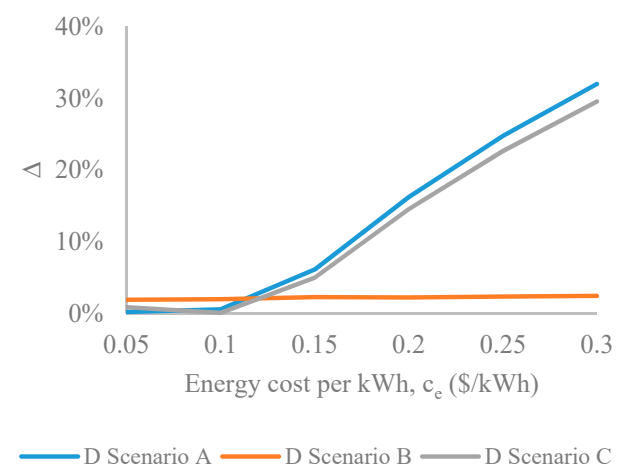

(a)

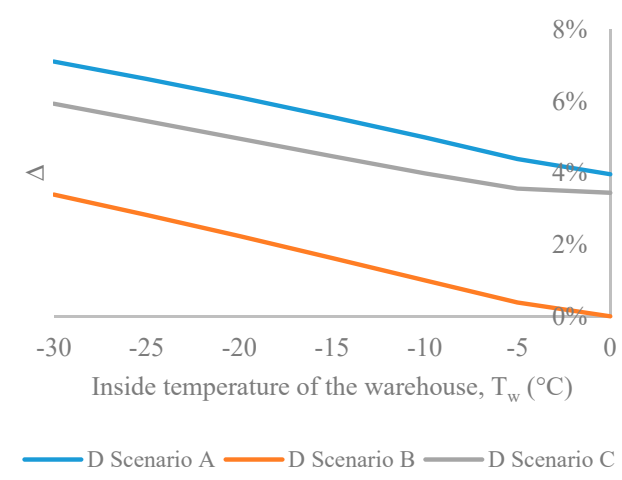

(b)

Figure 5. The behavior of the percentage error in total cost from not considering the filling level and/or temperature adjustment, $\Delta$, for changes in the values of (a) the unit energy cost, $c_{e}$ and (b) the temperature set inside the warehouse, $T_{w}$.

\section{Conclusions}

This paper investigated the effect of energy consumption on the economic order quantity model when products are stored in refrigerated warehouses. The temperature inside the warehouse must be set to a value that guarantees the proper cold storage condition to preserve the product quality, where energy demand is determined by the duration of the cooling period. Moreover, it should be considered that from real observations, a lower filling level required more energy. The inventory model proposed in this paper considered the combined effects of temperature, storage time, and filling level when investigating energy consumption and the total inventory costs. The numerical results highlighted the relevance of jointly considering both aspects. Neglecting those led to sub-optimal lot-sizing decisions and, subsequently, a higher total cost up to $12 \%$ in the numerical investigation reported. Scenarios that did not consider the filling level and temperature adjustments suggested larger optimal lot sizes, reducing the number of orders to meet the customer demand, and in the warehouse becoming empty in every cycle, leading to a noticeable increase in energy consumption. The effects of the two aspects considered on the total costs slightly compensated one another, i.e., considering both resulted in better system performance than considering temperature alone. Results also showed how the filling level has the most effect on the models when refrigeration requirements increased, e.g., due to higher energy cost per $\mathrm{kWh}$ and lower internal temperature. The findings of this study were very relevant to the food industry as they suggested reducing energy consumption and its related costs, which represent a significant share of the total cost of a cold chain. However, the developed model had some limitations. For instance, it did not consider the effects that temperature had on product quality, which is affected by the cooling requirements (e.g., perishable foodstuff). Hence, future research may consider the integration of product quality and loss in value as a function of the warehouse storage temperature and the cooling process; see, e.g., [12]. Additionally, along the lines of [32], which showed a possible energy state classification, it is possible to develop an energy optimization strategy. Moreover, one can assess if door openings affect energy consumption. For instance, the frequent opening of a refrigerator 
door during loading and unloading of goods could result in some of the cooled air escaping, which increases the energy load. Such losses could result in several undesirable phenomena, such as water condensation from the vapor and frost forming on the walls inside the warehouse and the transport vehicle. As the temperature inside a transport vehicle increases, deviating from the optimal value to preserve transported (perishable) goods, those goods could be compromised and may result in spoilage and disposal.

Author Contributions: Conceptualization, B.M., S.Z., and M.Y.J.; writing, original draft preparation, B.M.; writing, review and editing, S.Z., and M.Y.J. All authors have read and agreed to the published version of the manuscript.

Funding: This research received no external funding.

Acknowledgments: M.Y. Jaber thanks the Natural Sciences and Engineering Research Council of Canada (NSERC) for supporting his research and Università degli Studi di Brescia for the in-kind research support.

Conflicts of Interest: The authors declare no conflict of interest.

\section{Abbreviations}

Parameters:

A $\quad$ order cost $(\$ /$ order $)$

$b \quad$ economies of scale coefficient for warehousing operations

$C\left(I_{\max }\right) \quad$ investment cost for building the refrigerated warehouse (\$)

$C_{0} \quad$ fixed cost associated with operating the warehouse (\$)

$C_{1} \quad$ unit variable warehousing cost per $\mathrm{m}^{3}$ of storage $\left(\$ / \mathrm{m}^{3}\right)$

$c_{e} \quad$ unit energy $\operatorname{cost}(\$ / \mathrm{kWh})$

$D \quad$ demand rate (unit/year)

$h \quad$ unit holding cost (\$/unit/year)

$I_{\max } \quad$ maximum storage capacity of the warehouse $\left(\mathrm{m}^{3}\right)$

$I(t) \quad$ inventory level at time $t\left(\mathrm{~m}^{3}\right)$

$m \quad$ lifetime of the warehouse (years)

$\rho_{T_{w}} \quad$ coefficient linking specific energy consumption (SEC) to different

$\rho_{T_{w}} \quad$ storage temperatures

SEC specific energy consumption $\left(\mathrm{kWh} / \mathrm{m}^{3}\right)$

$\tau \quad$ length of the consumption cycle (year)

$T_{r} \quad$ warehouse reference temperature to the SEC value $\left({ }^{\circ} \mathrm{C}\right)$

Decision variables:

Q order lot size (unit)

$S \quad$ minimum inventory kept in the warehouse (unit)

$T_{w} \quad$ effective warehouse temperature $\left({ }^{\circ} \mathrm{C}\right)$

\section{References}

1. Gwanpua, S.G.; Verboven, P.; Leducq, D.; Brown, T.; Verlinden, B.E.; Bekele, E.; Aregawi, W.; Evans, J.; Foster, A.; Duret, S.; et al. The FRISBEE tool, a software for optimising the trade-off between food quality, energy use, and global warming impact of cold chains. J. Food Eng. 2015, 148, 2-12. [CrossRef]

2. Coulomb, D. Refrigeration and cold chain serving the global food industry and creating a better future: Two key IIR challenges for improved health and environment. Trends Food Sci. Technol. 2008, 19, 413-417. [CrossRef]

3. James, S.J.; James, C.; Evans, J.A. Modelling of food transportation systems-a review. Int. J. Refrig. 2006, 29, 947-957. [CrossRef]

4. Food, Drink Europe Data \& Trends: EU Food \& Drink Industry; Food Drink Europe: Brussels, Belgium, 2018.

5. Vanek, F.; Sun, Y. Transportation versus perishability in life cycle energy consumption: A case study of the temperature-controlled food product supply chain. Transp. Res. Part D 2008, 13, 383-391. [CrossRef]

6. Laguerre, O.; Hoang, H.M.; Gennes, G. De Experimental investigation and modelling in the food cold chain: Thermal and quality evolution. Trends Food Sci. Technol. 2013, 29, 87-97. [CrossRef] 
7. Facility Type: Supermarkets and Grocery Stores. In Building Upgrade Manual; Energy Star; 2008. Available online: https://www.energystar.gov/sites/default/files/buildings/tools/EPA_BUM_CH11_Supermarkets.pdf (accessed on 6 March 2020).

8. Geppert, J.; Stamminger, R. Do consumers act in a sustainable way using their refrigerator? The influence of consumer real life behaviour. Int. J. Consum. Stud. 2010, 34, 219-227. [CrossRef]

9. Saidur, R.; Masjuki, H.H.; Choudhury, I.A. Role of ambient temperature, door opening, thermostat setting position and their combined effect on refrigerator-freezer energy consumption. Energy Convers. Manag. 2002, 43, 845-854. [CrossRef]

10. Harris, F.W. How many parts to make at once. Factory Mag. Manag. 1913, 10, 135-136, 152. [CrossRef]

11. Zavanella, L.E.; Marchi, B.; Zanoni, S.; Ferretti, I. Energy considerations for the economic production quantity and the joint economic lot sizing. J. Bus. Econ. 2019, 89, 845-865. [CrossRef]

12. Zanoni, S.; Zavanella, L. Chilled or frozen? Decision strategies for sustainable food supply chains. Int. J. Prod. Econ. 2012, 140, 731-736. [CrossRef]

13. Hasanov, P.; Jaber, M.Y.; Tahirov, N. Four-level closed loop supply chain with remanufacturing. Appl. Math. Model. 2019, 66, 141-155. [CrossRef]

14. Bazan, E.; Jaber, M.Y.M.Y.; Zanoni, S. A review of mathematical inventory models for reverse logistics and the future of its modeling: An environmental perspective. Appl. Math. Model. 2016, 40, 4151-4178. [CrossRef]

15. Marchi, B.; Zanoni, S.; Jaber, M.Y. Economic production quantity model with learning in production, quality, reliability and energy efficiency. Comput. Ind. Eng. 2019, 129, 502-511. [CrossRef]

16. Marchi, B.; Zanoni, S.; Zavanella, L.E.; Jaber, M.Y. Supply chain models with greenhouse gases emissions, energy usage, imperfect process under different coordination decisions. Int. J. Prod. Econ. 2019, 211, 145-153. [CrossRef]

17. Biel, K.; Glock, C.H. On the use of waste heat in a two-stage production system with controllable production rates. Int. J. Prod. Econ. 2016, 181, 174-190. [CrossRef]

18. Marchi, B.; Zanoni, S.; Pasetti, M. A supply chain model with integrated thermal recovery and electricity generation from industrial waste heat. In Proceedings of the ECEEE Industrial Summer Study on Industrial Efficiency: Leading the Low-Carbon Transition, Kalkscheune, Berlin, Germany, 11-13 June 2018; pp. 181-188.

19. Zanoni, S.; Mazzoldi, L.; Ferretti, I. Eco-efficient cold chain networks design. Int. J. Sustain. Eng. 2018, 12, 1-16. [CrossRef]

20. Saif, A.; Elhedhli, S. Cold supply chain design with environmental considerations: A simulation-optimization approach. Eur. J. Oper. Res. 2016, 251, 274-287. [CrossRef]

21. Wei, C.; Gao, W.; Hu, Z.; Yin, Y.; Pan, S. Assigning customer-dependent travel time limits to routes in a cold-chain inventory routing problem. Comput. Ind. Eng. 2019, 133, 275-291. [CrossRef]

22. Meneghetti, A.; Ceschia, S. Energy-efficient frozen food transports: The refrigerated routing problem. Int. J. Prod. Res. 2019, 0, 1-18. [CrossRef]

23. Hariga, M.; As'ad, R.; Shamayleh, A.; As, R.; Shamayleh, A. Integrated economic and environmental models for a multi stage cold supply chain under carbon tax regulation. J. Clean. Prod. 2017, 166, 1357-1371. [CrossRef]

24. Bozorgi, A.; Pazour, J.; Nazzal, D. A new inventory model for cold items that considers costs and emissions. Int. J. Prod. Econ. 2014, 155, 114-125. [CrossRef]

25. Bozorgi, A. Multi-product inventory model for cold items with cost and emission consideration. Int. J. Prod. Econ. 2016, 176, 123-142. [CrossRef]

26. Rao, A.K.; Rao, M.R. Solution procedures for sizing of warehouses. Eur. J. Oper. Res. 1998, 108, $16-25$. [CrossRef]

27. Hall, R.W. Pickup and delivery systems for overnight carriers. Transp. Res. Part A Policy Pract. 1996, 30, 173-187. [CrossRef]

28. Hertog, M.L.A.T.M.; Uysal, I.; McCarthy, U.; Verlinden, B.M.; Nicolaï, B.M. Shelf life modelling for first-expired-first-out warehouse management. Philos. Trans. R. Soc. A Math. Phys. Eng. Sci. 2014, 372, 20130306. [CrossRef]

29. James, C.; Onarinde, B.A.; James, S.J. The Use and Performance of Household Refrigerators: A Review. Compr. Rev. Food Sci. Food Saf. 2017, 16, 160-179. [CrossRef]

30. Department for Environment Food \& Rural Affairs. Greenhouse Gas Impacts of Food Retailing; Defra: London, UK, 2008. 
31. El Saadany, A.M.A.; Jaber, M.Y. A production/remanufacturing inventory model with price and quality dependant return rate. Comput. Ind. Eng. 2010, 58, 352-362. [CrossRef]

32. Zanoni, S.; Ferretti, I.; Zavanella, L.E. Energy value stream methods with auxiliary systems. In Proceedings of the ECEEE Industrial Summer Study on Industrial Efficiency: Leading the Low-Carbon Transition, Kalkscheune, Berlin, Germany, 11-13 June 2018; pp. 281-291. 